\title{
Lipid Composition and Fluidity in the Jejunal Brush-Border Membrane of Spontaneously Hypertensive Rats. Effects on Activities of Membrane-Bound Proteins
}

\author{
Carmen M. Vázquez,, ${ }^{1,3}$ Rosana Zanetti, ${ }^{2}$ and \\ Valentina Ruiz-Gutierrez ${ }^{2}$
}

Received September 12, 1995; accepted November 15, 1995

\begin{abstract}
The lipid composition and fluidity of jejunal brush-border membrane vesicles (BBMV) have been studied in spontaneously hypertensive rats (SHR) and normotensive Wistar Kyoto (WKY) rats. The activities of both $\mathrm{Na}^{+}$-dependent $\mathrm{D}$-glucose cotransport and $\mathrm{Na}^{+} \cdot \mathrm{H}^{+}$antiport have also been determined. A significant increase in the level of free cholesterol was observed in jejunal BBMV from SHR compared to WKY rats. Since phospholipid values did not change in either group of animals, a significant enhancement in the free cholesterol/phospholipid ratio was observed in SHR. A decrease in the levels of phosphatidylethanolamine together with an increase in the values of phosphatidylserine was observed in hypertensive rats. Although the content of phosphatidylcholine (PC) and sphingomyelin (SM) was not singificantly altered in SHR, the ratio PC/SM significantly increased in these animals when compared to WKY rats. The major fatty acids present in bursh-border membranes prepared from SHR and WKY rats were palmitic (16:0), stearic (18:0), oleic $(18: 1, \mathrm{n}-9)$ and linoleic $(18: 2, \mathrm{n}-6)$, and the fatty acid composition was not modified by the hypertension. A decreased fluorescence polarization, i.e., increased membrane fluidity, was observed in SHR, which was not correlated to the increased ratio of cholesterol/phospholipid found in the brush-border membrane isolated from these animals. These structural changes found in SHR were associated to an enhancement in both $\mathrm{Na}^{+}$-dependent $\mathrm{D}$-glucose transport and $\mathrm{Na}^{+}-\mathrm{H}^{+}$antiport activity in the jejunal BBMV of SHR.
\end{abstract}

KEY WORDS: Spontaneously hypertensive rat; brush-border membrane; lipid fluidity; lipid composition; D-glucose; $\mathrm{Na}^{+}-\mathrm{H}^{+}$exchanger.

ABBREVIATIONS: BBMV, brush-border membrane vesicles; DPH, 1,6-diphenyl-1,3,5-hexatriene; FC, free cholesterol; PC, phosphatidylcholine; PE, phosphatidylethanolamine; PI, phosphatidylinositol; PS, phosphatidylserine; SM, sphingomyelin; SHR, spontaneously hypertensive rat; $p$, steady-state fluoroscence polarization; $r_{\mathrm{s}}$, steady-state fluorescence anisotropy; WKY, Wistar Kyoto.

\footnotetext{
${ }^{1}$ Departamento de Fisiología y Biologia Animal, Facultad de Farmacia, Universidad de Sevilla, C/Tramontana s/n, Universidad de Sevilla, 41012 Sevilla, España.

${ }^{2}$ Instituto de la Grasa y sus Derivados (CSIC), 41012 Sevilla, España.

${ }^{3}$ To whom correspondence should be addressed.
} 


\section{INTRODUCTION}

Hypertension has been associated to multiple abnormalities in cell membrane functions $(1,2)$, including the mobilization of intracellular calcium stores (3), changes in $\mathrm{Na}^{+}-\mathrm{K}^{+}$cotransport, $\mathrm{Na}^{+}-\mathrm{Li}^{+}$countertransport and $\mathrm{Na}^{+}-\mathrm{H}^{+}$exchan$\operatorname{ger}(4,5)$.

It has been suggested that a generalized physico-chemical alteration of the lipid bilayer, the matrix in which all the membrane proteins function, may be responsible for these multiple membrane abnormalities $(6,7,8)$. Thus, previous reports have found consistent differences in the lipid composition of erythrocyte and platelet membranes and other tissues in hypertension $(9,10,11)$.

In addition, changes in the lipid composition of erythrocyte and intestinal brush-border membranes by dietary lipid modifications $(12,13)$ have been shown to alter the physical properties of the membrane, resulting in modifications of the lipid-protein interaction which in turn might influence the function of a wide variety of intrisic and extrinsic membrane-bound proteins.

In this study we explored the lipid composition and fluidity of jejunal brush-border membranes from spontaneously hypertensive (SHR) and normotensive-control (WKY) rats. Taking into account the association between such parameters and the function of membrane-bound proteins, we also examined the activity of two membrane-bound proteins such as $\mathrm{Na}^{+}$-dependent $\mathrm{D}$-glucose transporter and $\mathrm{Na}^{+}-\mathrm{H}^{+}$exchanger.

The results described below demonstrate that jejunal brush-border membranes from SHR, when compared to those from WKY rats, had increased the cholesterol-phospholipid ratio, the lipid fluidity and, concomitantly, both $\mathrm{Na}^{+}$dependent $\mathrm{D}$-glucose transport and $\mathrm{Na}^{+}-\mathrm{H}^{+}$antiport activity.

\section{MATERIALS AND METHODS}

\section{Materials}

D-(U- $\left.{ }^{14} \mathrm{C}\right)$ Glucose $(283 \mathrm{mCi} / \mathrm{mmol})$ was purchased from Amersham International. Sodium ${ }^{22}$ as sodium chloride $(253 \mathrm{mCi} / \mathrm{mg})$ was purchased from Dupont NEN. Membrane filters (Millipore GSWP02500) were obtained from Millipore Products Division, U.K. All other chemicals were supplied by Sigma.

\section{Animal Model}

Male SHR and WKY rats were obtained at the age of 8-9 weeks from IFFA CREDO (France). Animals had free access to food and water. All experiments were performed on 10-12 week-old-rats, which were fasted during $18 \mathrm{~h}$ before sacrifice. 


\section{Brush-Border Membrane Vesicles Preparation}

Brush-border membrane vesicles (BBMV) were isolated from the jejunal mucosa by the $\mathrm{MgCl}_{2}$ precipitation method (14) with slight modifications. The mucosal scrapings were homogenized for $3 \mathrm{~min}$ in $100 \mathrm{mM}$ mannitol, $2 \mathrm{mM}$ HEPES/Tris, pH 7.1, using a Waring blender at maximal speed. The homogenate was treated with $10 \mathrm{mM} \mathrm{MgCl}_{2}$ and centrifuged at $3000 \mathrm{~g}$ for $30 \mathrm{~min}$. The following steps were taken as previously described (14). All isolation steps were carried out on ice. Aliquots of BBMV were stored under liquid nitrogen until analysis. Isolated BBMV were checked by determination of the specific activity of the brush-border membrane marker enzyme sucrase with the method of Dahlquist (15). The final brush-border membrane fraction showed a 18-21 fold enrichment in sucrase activity with respect to the original homogenate in both groups of animals. Cross contamination with the basolateral membrane was negligible, as there was no enrichment of $\mathrm{Na}^{+}-\mathrm{K}^{+}$-ATPase (16). Protein was measured by a Coomassie Brilliant Blue protein assay using bovine gammaglobulin as standard (17).

\section{Lipid Analysis}

Total lipids were extracted from the brush-border membrane by the method of Folch (18) using chloroform/methanol $(2: 1, \mathrm{v} / \mathrm{v})$ as the solvent system and $0.02 \%(\mathrm{w} / \mathrm{v})$ butylated hydroxytoluene as antioxidant. Lipid and phospholipid compositions were obtained by means of the Iatroscan TLC/FID technique (19). The Iatroscan MK-5 was used in combination with Chromarods S, having a precoated active silica thin layer. Chromarods $S$ were routinely stored in $4.5 \mathrm{M}$ $\mathrm{H}_{2} \mathrm{SO}_{4}$. Prior to use, the rods were washed with distilled water, dried at $100^{\circ} \mathrm{C}$ for $15 \mathrm{~min}$ and activated by being passed through the flame of the Iatroscan detector. Three $\mu 1$ of total lipids or phospholipids was spotted on each rod using a $10 \mu \mathrm{l}$ Hamilton syringe. To separate total lipids, rods were developed in hexane/diethyl ether/acetic acid $(80: 20: 1, \mathrm{v} / \mathrm{v} / \mathrm{v})$. The phospholipids were resolved in two steps, starting with an initial development of rods in chloroform/methanol/acetic acid/water $(201: 84: 9: 6, \mathrm{v} / \mathrm{v} / \mathrm{v} / \mathrm{v})$, drying at $70^{\circ} \mathrm{C}$ for $10 \mathrm{~min}$, and a second development in hexane/diethyl ether/acetic acid $(80: 20: 1, \mathrm{v} / \mathrm{v} / \mathrm{v})$. Rods were scanned under the following conditions: hydrogen flow, $150 \mathrm{ml} / \mathrm{min}$; air flow, $1750 \mathrm{ml} / \mathrm{min}$; scanning speed, $47 \mathrm{~mm} / \mathrm{s}$; chart speed, $42 \mathrm{~mm} / \mathrm{min}$. A Iatrocorder TC-11 integrator was used for recording and area integration.

\section{Fatty Acid Analysis}

Fatty acids of the total lipid extract were analyzed by gas chromatography (GC). The samples were saponified by heating for $5 \mathrm{~min}$ with $5 \mathrm{ml}$ of $0.2 \mathrm{M}$ sodium methylate and heated again at $80^{\circ} \mathrm{C}$ for 5 min with $6 \%(w / v) \mathrm{H}_{2} \mathrm{SO}_{4}$ in anhydrus methanol. The fatty acid methyl esters thus formed were eluted with hexane, and analyzed in a Hewlett-Packard 5890 series II gas chromatograph equipped with a flame ionization detector and using an Omegawax 320 fused 
silica capillary column $(30 \mathrm{~m} \times 0.32 \mathrm{~mm}$ i.d., $0.25 \mu \mathrm{m}$ film $)$. The initial column temperature was $200^{\circ} \mathrm{C}$, which was maintained for $10 \mathrm{~min}$, then programmed from $200-230^{\circ} \mathrm{C}$ at $2^{\circ} \mathrm{C} / \mathrm{min}$. The injection and detector temperatures were $250^{\circ} \mathrm{C}$ and $260^{\circ} \mathrm{C}$, respectively. The flow rate of helium was $2 \mathrm{ml} / \mathrm{min}$, the column head pressure was $250 \mathrm{kPa}$ and the detector auxiliary flow rate was $25 \mathrm{ml} / \mathrm{min}$. Peak areas were calculated by a Hewlett-Packard 3990A recording integrator. Individual fatty acid methyl esters were identified on isothermal runs by comparison of their retention time against those of standards. Fatty acid methyl esters were quantified by internal standardization (tricosanoic methyl ester, 23:0), using peak-area integration.

\section{Fluorescence Measurement}

The steady-state fluorescence polarization $(p)$ and fluorescence anisotropy $\left(r_{s}\right)$ were determinated as previously described (20), using the lipid-soluble fluorescent probe 1,6-diphenyl-1,3,5-hexatriene (DPH). A stock solution of $2 \mathrm{mM}$ $\mathrm{DPH}$ in tetrahydrofuran was prepared and stored in the dark at $-30^{\circ} \mathrm{C}$. BBMV equivalent to $100 \mu \mathrm{g}$ protein were incubated at $25^{\circ} \mathrm{C}$ for $1 \mathrm{~h}$ in $2 \mathrm{ml}$ of buffered saline containing $250 \mathrm{mM}$ sucrose, $10 \mathrm{mM}$ Tris- $\mathrm{HCl}, \mathrm{pH} 7.4$ and $2 \mu \mathrm{M} \mathrm{DPH}$. Measurements were taken using a Perkin-Elmer 650-40 fluorescence spectrophotometer equipped with a polarizing filter. The excitation and emission wavelengths were 365 and $430 \mathrm{~nm}$, respectively. The steady-state fluorescence polarization ( $p$ ) was calculated as

$$
\mathrm{p}=(\mathrm{Ivv}-\mathrm{Ivh} / \mathrm{Ivv}+\mathrm{Ivh})
$$

where Ivv and Ivh are observed intensities measured with polarizers parallel to and perpendicular to, respectively, the vertically oriented polarizer exciting beam. The steady-state fluorescence anisotropy $\left(r_{s}\right)$ was calculated from the ratio

$$
\mathrm{rs}=2 \mathrm{p} /(3-\mathrm{p})
$$

where $\mathrm{p}$ is the fluoroescence polarization.

Corrections for light scattering were routinely made by subtracting the signal obtained from identical but unlabelled samples: this contributed less than $3 \%$ to the fluorescence of the complete system.

The vesicles were used for fluorescence polarization studies immediately after preparation.

\section{Uptake Studies}

The uptake of $\mathrm{D}$-glucose was measured at $25^{\circ} \mathrm{C}$ by a rapid filtration technique. BBMV were suspended in a medium containing $300 \mathrm{mM}$ mannitol, $0.1 \mathrm{mM} \mathrm{MgSO}_{4}, 0.02 \%(\mathrm{w} / \mathrm{v}) \mathrm{NaN}_{3}$ and $20 \mathrm{mM} \mathrm{HEPES} / \mathrm{Tris}, \mathrm{pH}$ 7.4. The assay was initiated by the addition of $100 \mu \mathrm{l}$ of the incubation medium to a suspension of BBMV (75-125 $\mu \mathrm{g}$ of protein). The incubation medium contained $100 \mathrm{mM}$ mannitol, $0.1 \mathrm{mM} \mathrm{MgSO}_{4}, 0.02 \%$ (w/v) $\mathrm{NaN}_{3}, 20 \mathrm{mM} \mathrm{HEPES/Tris,} \mathrm{pH} \mathrm{7.4,}$ $0.1 \mathrm{mM}{ }^{14} \mathrm{C}$-D-glucose and either $100 \mathrm{mM}$ NaSCN or $100 \mathrm{mM} \mathrm{KSCN}$. The uptake 
was terminated by the addition of an ice-cold stop solution. The stop solution contained $150 \mathrm{mM} \mathrm{KSCN}, 0.1 \mathrm{mM} \mathrm{MgSO}_{4}, 0.02 \%$ (w/v) $\mathrm{NaN}_{3}, 0.25 \mathrm{mM}$ phlorizin, and $20 \mathrm{mM}$ HEPES/Tris, $\mathrm{pH}$ 7.4. The BBMV were separated from the incubation medium by filtering on a $0.22 \mu \mathrm{m}$ pore size Millipore filter. The filter was washed with $5 \mathrm{ml}$ of stop solution. The radioactivity retained on the filter was measured using a scintillation counter. The uptake at time zero was measured and substracted from the total radioactivity of each sample. All experiments were performed in duplicate.

For the $\mathrm{Na}^{+}$uptake, BBMV were suspended in a medium containing $300 \mathrm{mM}$ mannitol, $50 \mathrm{mM}$ potassium gluconate and $20 \mathrm{mM}$ MES/Tris, pH 5.5. The assay was initiated by the addition of $100 \mu \mathrm{l}$ of the incubation medium to 8-10 $\mu$ l of a suspension of BBMV (equivalent to $100-150 \mu \mathrm{g}$ of protein). The uptake was quenched by the addition of $1 \mathrm{ml}$ of an ice-cold stop solution. The incubation medium contained $300 \mathrm{mM}$ mannitol, $50 \mathrm{mM}$ potassium gluconate, $0.1 \mathrm{mM}$ sodium gluconate, $45 \mu \mathrm{M}$ valinomycin, tracers of ${ }^{22} \mathrm{Na}^{+}$and iether $20 \mathrm{mM}$ MES/Tris (pH 5.5) or $20 \mathrm{mM}$ HEPES/Tris ( $\mathrm{pH} 7.5$ ). The stop solution contained $300 \mathrm{mM}$ mannitol, $50 \mathrm{mM}$ potassium gluconate and $20 \mathrm{mM} \mathrm{MES} /$ Tris (pH 5.5).

\section{Statistical Treatment of the Results}

Results are expressed as the mean \pm SE. The statistical significance of the differences between groups was determined by the Student's t-test. Differences were considered significant when $p<0.05$.

\section{RESULTS}

\section{Lipid Composition}

Brush-border membrane lipid composition of SHR and WKY rats are shown in Table 1. Free fatty acid levels were similar for both SHR and WKY rats. However, a significant increase in the level of free cholesterol was observed in SHR compared to WKY rats. Since phospholipid values did not change in either

Table 1. Lipid composition of jejunal BBMV prepared from SHR and WKY rats

\begin{tabular}{lcc}
\hline & \multicolumn{2}{c}{ Percentage (w/w) of total lipid } \\
\cline { 2 - 3 } Lipid & WKY & SHR \\
\hline Phospholipids & $64 \pm 4.6$ & $58 \pm 2.6$ \\
Free fatty acids & $29 \pm 4.3$ & $32 \pm 3.0$ \\
Free cholesterol & $9.8 \pm 0.8$ & $20 \pm 2.7^{* *}$ \\
Free cholesterol/Phospholipid & $0.2 \pm 0.02$ & $0.5 \pm 0.12^{*}$ \\
\hline
\end{tabular}

Results are means \pm SE for at least eight different preparations. $* \mathrm{p}<0.05$,

$* * \mathrm{p}<0.025$ compared to WKY rats. 
Table 2. Phospholipid composition of jejunal BBMV prepared from SHR and WKY rats

\begin{tabular}{lcc}
\hline & \multicolumn{2}{c}{ Percentage $(w / w)$ of total phospholipid } \\
\cline { 2 - 3 } Phospholipid & WKY & SHR \\
\hline Phosphatidylethanolamine & $48 \pm 5.7$ & $35 \pm 1.5^{* *}$ \\
Phosphatidylserine & $34 \pm 6.3$ & $50 \pm 3.1^{* *}$ \\
Phosphatidylcholine & $14 \pm 3.1$ & $10 \pm 1.2$ \\
Sphingomyelin & $4.1 \pm 0.5$ & $3.2 \pm 0.3$ \\
Phosphatidylinositol & $<1$ & $<1$ \\
Phosphatidylcholine/Sphingomyelin & $2.1 \pm 0.3$ & $3.7 \pm 0.5^{*}$ \\
\hline
\end{tabular}

Results are means $\pm \mathrm{SE}$ for at least eight different preparations.

$* p<0.05$,

** $p<0.025$ compared to WKY rats.

group of animals, a significant enhancement in the free cholesterol/phospholipid ratio was observed in the hypertensive rats. Phospholipid composition of jejunal BBMV for SHR and WKY rats is shown in Table 2. Respective phosphatidylethanolamine (PE) and phosphatidylserine (PS) levels were significantly decreased and increased in SHR compared to WKY rats. Although the content of phosphatidylcholine (PC) and sphingomyelin (SM) was not significantly altered by hypertension, the PC/SM ratio was significantly increased in SHR. No significant differences were noted in the total fatty acid composition of jejunal BBMV prepared from either SHR or WKY rats (Table 3). As shown in this

Table 3. Fatty acid composition of jejunal BBMV prepared from SHR and WKY rats

\begin{tabular}{|c|c|c|}
\hline \multirow[b]{2}{*}{ Component } & \multicolumn{2}{|c|}{ Composition $(\% \mathrm{w} / \mathrm{w})$} \\
\hline & WKY & SHR \\
\hline \multicolumn{3}{|l|}{ Fatty acid } \\
\hline $14: 0$ & $1.5 \pm 0.33$ & $2.5 \pm 0.6$ \\
\hline $16: 0$ & $21.4 \pm 3.7$ & $26.8 \pm 0.9$ \\
\hline $16: 1(n-7)$ & $5.3 \pm 1$ & $5.2 \pm 1.2$ \\
\hline $18: 0$ & $14.4 \pm 1.7$ & $13.6 \pm 2.5$ \\
\hline $18: 1(n-9)$ & $27.3 \pm 3.7$ & $22.6 \pm 2.3$ \\
\hline $18: 1(n-7)$ & $3.9 \pm 0.2$ & $2.9 \pm 0.5$ \\
\hline $18: 2(n-6)$ & $14.1 \pm 1.5$ & $13 \pm 1.2$ \\
\hline $20: 3(n-9)$ & $0.6 \pm 0.06$ & $0.6 \pm 0.1$ \\
\hline $20: 4(n-6)$ & $7.4 \pm 0.8$ & $7.0 \pm 1.6$ \\
\hline $22: 6(n-3)$ & $0.7 \pm 0.1$ & $0.7 \pm 0.1$ \\
\hline \multicolumn{3}{|l|}{ Classes } \\
\hline Saturated & $38.1 \pm 6.0$ & $43.7 \pm 2.5$ \\
\hline Monounsaturated & $39.1 \pm 5.5$ & $31.1 \pm 3.8$ \\
\hline Polyunsaturated & $22.8 \pm 0.5$ & $23.9 \pm 0.6$ \\
\hline$(n-3)$ & $0.9 \pm 0.2$ & $1.1 \pm 0.2$ \\
\hline$(n-6)$ & $22.5 \pm 0.3$ & $20.7 \pm 1.4$ \\
\hline Ratios & & \\
\hline sat/unsat & $0.63 \pm 0.16$ & $0.81 \pm 0.09$ \\
\hline
\end{tabular}

Results are means $\pm \mathrm{SE}$ for four separate preparations of each membrane. 
Table 4. Steady-state fluorescence polarization and steady-state fluorescence anisotropy of jejunal BBMV prepared from SHR and WKY rats; $r_{s}$, fluorescence anisotropy

\begin{tabular}{lcc}
\hline Parameter & WKY & SHR \\
\hline $\mathrm{p}_{\mathrm{DPH}}$ & $0.342 \pm 0.008$ & $0.262 \pm 0.006^{*}$ \\
$\mathrm{r}_{\mathrm{s}}$ & $0.257 \pm 0.007$ & $0.191 \pm 0.005^{*}$ \\
\hline
\end{tabular}

Results are means $\pm S E$ for at least ten different preparations.

${ }_{*} p<0.001$ compared to WKY rats.

$\mathrm{P}_{\mathrm{DPH}}$, fluoroscence polarization.

Table, the major fatty acids present were palmitic (16:0), stearic (18:0), oleic $(18: 1, n-9)$ and linoleic (18:2, n-6). Arachidonic (20:4,n-6) and palmitoleic $(16: 1$, $n-7)$ acids ranged between 5 and $7 \%$ of the total fatty acids. High contents of fatty acids from the $n-6$ family were also found in both preparations. In contrast, $n-3$ fatty acids were noted in small amounts in BBMV of both groups of animals. An increase, although not significant, was found in the ratio saturated/unsaturated fatty acid of SHR compared to WKY rats.

\section{Membrane Fluidity}

The steady-state fluorescence polarization $(\mathrm{p})$ and fluorescence anisotroy $\left(\mathrm{r}_{\mathrm{s}}\right)$ data for DPH-labeled jejunal brush-border membrane preparations from SHR and WKY rats are given in Table 4. There was a highly significant decrease in both parameters in brush-border membranes prepated from SHR, compared to those from WKY rats.

\section{D-glucose and $\mathrm{Na}^{+}$uptake}

Table 5 shows the initial rates of both $\mathrm{Na}^{+}$-dependent $\mathrm{D}$-glucose uptake and pH-gradient dependent $\mathrm{Na}^{+}$uptake measured in SHR and WKY rats. The $\mathrm{Na}^{+}$-dependent D-glucose rate was increased 5.8-fold in SHR. However, the $\mathrm{pH}$-gradient $\mathrm{Na}^{+}$uptake was only increased in SHR by 2.7 -fold when compared to WKY rats.

Table 5. $\mathrm{Na}^{+}$-dependent $\mathrm{D}$-glucose uptake and $\mathrm{pH}$-gradient ( $\mathrm{pH} 5.5$ inside, 7.5 outside) $\mathrm{Na}^{+}$uptake in jejunal BBMV prepared from SHR and WKY rats

\begin{tabular}{lcc}
\hline & $\begin{array}{c}\text { D-glucose uptake } \\
\left(\mathrm{pmol} \cdot \mathrm{mg} \cdot \mathrm{s}^{-1}\right)\end{array}$ & $\begin{array}{c}\mathrm{Na}^{+} \text {uptake } \\
\left(\mathrm{pmol} \cdot \mathrm{mg} \cdot \mathrm{s}^{-1}\right)\end{array}$ \\
\hline WKY & $36 \pm 7$ & $5.5 \pm 0.8$ \\
SHR & $209 \pm 32^{* *}$ & $15 \pm 3.4^{*}$ \\
\hline
\end{tabular}

Results are means $\pm \mathrm{SE}$ for at least six different preparations. ${ }^{*} \mathrm{p}<0.025$,

${ }^{* *} \mathrm{p}<0.001$ compared to WKY rats. 


\section{DISCUSSION}

Our data indicate differences in the lipid composition of jejunal brush-border membranes prepared from SHR and WKY rats. Free cholesterol content of these membranes is increased in SHR compared to WKY rats. Since phospholipid levels were not altered by hypertension, a significant increment in the molar ratio of free cholesterol/phospholipid was observed in SHR. An increased cholesterol/phospholipid ratio has been previously reported in erythrocyte (9) and platelet (10) membranes of essential hypertensive patients.

To check whether the phospholipid composition changes in SHR, the phospholipid species were quantified. The predominant phospholipids in the control group, WKY rats, were PE and PS. This finding was not similar to that described by Bjorkman and Brigham (21) and Christon et al. (22), who indicated that $\mathrm{PC}$ together with $\mathrm{PE}$ were the predominant phospholipids in the whole small intestine from normotensive rats. These differences might be due to the portion of the intestine used, since our study was focussed only on the jejunum phospholipid composition. PE and PS were also the major phospholipids extracted from jejunum of SHR. However, PE levels were significantly decreased and PS levels increased in the SHR group. PC and SM levels did not significantly alter by hypertension, however, the PC/SM ratio was significantly increased in SHR.

The level of phosphatidylinositol (PI) found in the jejunal brush-border membrane prepared from SHR and WKY rats is less than $1 \%$. It is accepted that inositol lipids are involved in signal transduction events and that a possible link between a global disturbance of cell membrane lipids and cell function, through membrane-based second messenger systems, may occur (23). In addition, disturbances of the phosphoinositide turnover have been reported in early stages of hypertension in SHR and man $(24,25)$. However, we have not found differences in the level of PI in either group of animals.

Membrane fluidity (the inverse of microviscosity) is a property of the membrane that describes quantitatively the mobility and rate of rotational movement of molecules within the membrane. Membrane fluidity is decreased in erythrocyte $(26,27)$, platelet (8) and vascular smooth muscle cell (7) membranes isolated from SHR. Devynck et al. (28) reported increments in microviscosity of the plasma membrane of SHR not only in erythrocytes, but also in hepatocytes, synaptosomes and cardiomyocytes, indicating that this membrane abnormality may affect the membrane structure and function of other tissues. Human essential hypertension is also characterized by increased membrane viscosity of erythrocyte and platelet membranes $(7,29,30)$. However, studies on platelets have shown an increase in the membrane fluidity of hypertensive patients (31).

Our results show a significant decrease in both the steady-state fluorescence polarization $(p)$ and fluorescence anisotropy $\left(r_{s}\right)$ in SHR when compared to those from WKY rats, indicating that brush-border membranes from SHR showed a higher fluidity than those from WKY rats. Previous studies in model and biological membrances $(32,33,34)$ have shown that differences in membrane fluidity may be secondary to alterations in the ratio cholesterol/phospholipid. An inverse relationship between brush-border membrane cholesterol/phospholipid 
ratio and membrane fluidity has been demonstrated. However, in our case, this inverse relationship did not exist, since an increase in the cholesterol/ phospholipid ratio in brush-border membranes prepared from SHR was accompanied by an increase in the membrane fluidity. The analysis of fatty acids in WKY rats revealed the presence of four major fatty acids, palmitic $(16: 0)$, stearic $(18: 0)$, oleic $(18: 1 \mathrm{n}-9)$ and linoleic $(18: 2 \mathrm{n}-6)$, as previously reported for rats (35) and other anomals (36). Hypertension did not produce large differences in the fatty acid composition of jejunal membranes, since it was similar for SHR. An increase, although not significant, in saturated-unsaturated ratio was also observed in SHR. Since the degree of fatty acyl chain unsaturation has been shown to be a determinant of membrane fluidity (37), these results do not explain the increased membrane fluidity (37), these results do not explain the increased membrane fluidity observed in SHR membranes. Consistent differences in the fatty acid composition of several tissues have been previously described between SHR and WKY rats, including renal medullary, renal cortical, brain and adrenal glands (11).

Concomitant with the changes in lipid composition and fluidity, we found an increase in both $\mathrm{Na}^{+}$-dependent $\mathrm{D}$-glucose transport and $\mathrm{Na}^{+}-\mathrm{H}^{+}$antiport activity in the jejunal BBMV prepared from SHR when compared to WKY rats. These results are not in agreement with previous experiments in which a decrease in $\mathrm{Na}^{+}$-dependent $\mathrm{D}$-glucose transport was noted in renal BBMV prepared from SHR (38). However, considerable evidence associates hypertension with the stimulation of the $\mathrm{Na}^{+}-\mathrm{H}^{+}$exchanger in lymphocytes (39), erythrocyte (40), platelet (41) and renal brush-border membranes (38) prepared from SHR. Similarly, essential hypertension in man is also characterized by an enhancement in $\mathrm{Na}^{+}-\mathrm{H}^{+}$exchanger (42).

Membrane lipid composition and fluidity can modulate the activity of ion transport pathways, including $\mathrm{Na}^{+}-\mathrm{K}^{+}$-ATPase, $\mathrm{Na}^{+}-\mathrm{Ca}^{2+}$ exchange, $\mathrm{Ca}^{2+}$ pump and $\mathrm{Na}^{+}+\mathrm{H}^{+}$exchanger $(43,44,45)$. In addition, previous studies have demonstrated a direct correlation between fluidity and $\mathrm{Na}^{+}$-dependent $\mathrm{D}$-glucose transport in rat small intestinal BBMV (46). Therefore, the differences in membrane lipid composition and fluidity noted between SHR and WKY rats could be responsible for alterations in membrane-bound proteins seen in hypertension. However, it is not clear whether altered membrane transport in SHR is due to extracellular factors or represents a basic plasma membrane abnormality as a metabolic consequence of the hypertensive status. Further studies are necessary to clarify these observations.

\section{ACKNOWLEDGEMENTS}

This work was supported by a grant ALI-92-0881 from the Comisión Interministerial de Ciencia y Technología (CICYT).

R. Zanetti was supported by a grant from Instituto de Cooperación Iberoamericano (ICI). 


\section{REFERENCES}

1. Postnov, Y. V. and Orlov, S. N. (1984) J Hypertension 2:1-6.

2. Bing, R. F., Heagerty, A. M., Thurston, H. and Swale, J. D. (1986) Clin. Sci. 71:415-425.

3. Furspan, P. and Bohr, D. F. (1986) Hypertension 8:II123-II126,

4. Weder, A. B. (1991) Am. J. Hypertension 4:6335-6375.

5. Berk, B. C., Vallega, G., Muslin, A. J., Gordon, H. M., Canessa, M. and Alexander, R. W. (1989) J. Clin. Invest. 83:822-829.

6. Dominiczak, A. F. and Bohr, D. F. (1990) Clin. Sci. 79:415-425.

7. Dominiczak, A. F., Lazar, D. F., Das, A. K. and Bohr., D. F. (1991) Hypertension 18:748-757.

8. Dominiczak, A. F. and Bohr, D. F. (1991) Am. J. Hypertension 4:963-969.

9. Preiss, R., Prumke, H. J., Sohr, R., Müller, E., Schmeck, G., Schmidt, J. et al. (1982) Int. J. Clin. Pharmacol. Ther. Toxicol. 20:105-112.

10. Benjamin, N., Robinson, B. F., Graham, J. G. and Wilson, R. B. (1990) J. Hum. Hypertension 4:273-276.

11. Watanabe, Y., Huang, Y.-S., Simmons, A. and Horrobin, D. F. (1989) Lipids 24:638-644.

12. Pagnan, A., Corrocher, R., Ambrosio, G. B., Ferrari, S., Guarini, P., Piccolo, D. et al. (1989) Clin. Sci. 76:87-93.

13. Brasitus, T. A., Dudeja, P. K., Bolt, M. J. G., Sitrin, M. D. and Baum, C. (1989) Biochim. Biophys. Acta 979:177-186.

14. Shirazi-Beechey, S. P., Davies, A. G., Dyer, T. J., Ellis, A., Taylor, C. J., Fairclough, P. and Beechey, R. B. (1990) Gastroenterology 98:676-685.

15. Dahlquist, A. (1964) Analytical Biochem. 7:18-25.

16. Kinne, R., Schmitz, J. E. and Kinne-Saffran, E. (1971) Pfluegers Arch. 329:191-209.

17. Bradford, M. M. (1976) Analytical Biochem. 72:248-254.

18. Folch, J., Less, M. and Sloan-Stanley, G. H. (1957) J. Biol. Chem. 33:497-509.

19. De Schrijver, R. and Vermeulen, D. (1991) Lipids 26:74-76.

20. Vorbeck, M. L., Martin, A. P., Long, J. W., Smith, J. M. and Orr, R. R. (1982) Arch. Biochem. Biophys. 217:351-361.

21. Bjorkman, D. J. and Brigham, E. J. (1990) Biochem. Biophys. Res. Comm. 170:433-440.

22. Christon, R., Meslin, J. C., Thévenoux, J., Linard, A., Léger, C. L. and Delpal, S. (1991) Reprod. Nutr. Dev. 31:691-701.

23. Heagerty, A. M. and Ollerenshaw, J. D. (1987) J. Hypertension 5:515-524.

24. Heagerty, A. M., Ollerenshaw, J. D. and Swales, J. D. (1986) Br. J. Pharmacol. 89:803-807.

25. Riozzi, A., Heagerty, A. M., Ollerenshaw, J. D., Swales, J. D. (1987) Clin. Sci. 73:29-32.

26. Tsuda, K., Tsuda, S., Minatogawa, Y., Iwahashi, H., Kido, R., Masuyama, Y. (1988) Clin. Sci. $75: 477-480$.

27. McLaren, Y., Kreutz, R., Lindpaintner, K., Bohr, D. F., Ganten, D., Reid, J. L. and Dominiczak, A. F. (1993) J. Hypertension 11:25-30.

28. Devynck, M. A., Pernollet, M. G., Nunez, A. M., Aragon, I., Montenay-Garestier, T., Helene, C. et al. (1982) Proc. Natl. Acad. Sci. USA 79:5057-5060.

29. Orlov, S. N. and Postnov, Y. V. (1982) Clin. Sci. 63:281-284.

30. Naftilan, A. J., Dzau, V. J. and Loscalzo, (1986) J. Hypertension 8: II19-II24.

31. Cooper, R. A. (1978) J. Supramol. Struct. 8:413-430.

32. Brasitus, T. A. and Dudeja, P. K. (1985) Arch. Biochem. Biophys. 240:483-488.

33. Shinitzky, M. and Barenholz, Y. (1978) Biochim. Biophys. Acta 5151:367-394.

34. Shinitzky, M. and Inbar, M. (1976) Biochim Biophys. Acta 433:133-149.

35. Heubi, J. E. and Fellows, J. (1985) J. Lipid Res. 26:797-805.

36. Davloose, D., Linard, A., Arfi, T., Viret, J. and Christon, R. (1993) Biochim Biophys Acta 1166:229-237.

37. Carriere, B. and Le Grimellec, C. (1986) Biochim. Biophys. Acta 857:131-138.

38. Morduchowicz, G. A., Sheikh-Hamad, D., Jo, Ok D., Nord, E. P., Lee, D. B. N. and Yanagawa, N. (1989) Kidney International 36:576-581.

39. Abdulkarim, M. S. and Beatle, D. C. (1990) J. Clin. Invest. 85:1734-1739.

40. Sierra, A., Coca, A., Paré, J. C., Sánchez, M., Compte, M., Azqueta, M. and Urbano-Márquez, A. (1993) J. Hypertension 11: $S 250-\mathrm{S} 251$.

41. Schmouder, R. L. and Weder, A. B. (1989) J. Hypertension 7:325-330.

42. Rosskopf, D., Düsing, R. and Siffert, W. (1993) Hypertension 21:607-617.

43. Poli de Figueiredo, C. E., Davies, J. E. and Cazana, F. J. L. (1991) J. Physiol. (Lond.) 432:26.

44. Davies, J. E. (1991) Am. J. Physiol. 261:C780-C786.

45. Schmalzing, G. and Kutschera, P. (1982) J. Membrane Biol. 69:65-76.

46. Brasitus, T. A. and Dudeja, P. K. (1985) J. Biol. Chem. 260:12404-12409. 